\section{Toxicidad ocular y cardíaca por cloroquina}

\section{Ocular and cardiac toxicity by chloroquine}

\section{Sr. Editor:}

El desarrollo de un bloqueo auriculoventricular completo (BAVC) es una manifestación conocida del lupus neonatal pero, sin embargo, en los adultos con lupus y BAVC no se ha demostrado que su causa sea una agresión inflamatoriavasculítica del sistema de conducción y, por tanto, hay que buscar otras etiologías del mismo.

Se comunica el caso de una mujer de 59 años con lupus eritematoso sistémico (ANA positivo $1 / 160$, anti ENAs y antiacoagulante lúpico negativos), que siguió tratamiento con cloroquina durante 13 años y hasta hace 15 días (dosis de 250 mg 6 días a la semana, acumulada de $936 \mathrm{~g}$ ) en que se retiró por detectarse signos de toxicidad ocular bilateral en un control oftalmológico; la paciente tenía una alteración pigmentaria macular bilateral en el fondo de ojo, test de Ishiara anómalo con 11/15 fallos, y escotoma central en la campimetría bilateral (Figura 1). Consultó ahora por fatigabilidad intensa de dos semanas de evolución, detectándose en el ECG la presencia de un bloqueo auriculoventricular completo a $30 \mathrm{lpm}$ con QRS ancho (Figura 2). La paciente no presentaba factores de riesgo cardiovascular ni historia de cardiopatía personal ni familiar; en el examen físico sólo destacaba palidez cutánea, la analítica urgente y de control (parámetros bioquímicos y hemograma, VHS y coagulación) y radiografía de tórax eran normales, y en el ecocardiograma sólo destacó un engrosamiento moderado de los velos valvulares aórticos y mitrales, sugestivo de afectación valvular lúpica. A pesar de la falta de un estudio anatomopatológico, la historia clínica de la paciente y los datos reportados en la literatura llevaron al diagnóstico final de cardiotoxicidad por cloroquina y, dada la severidad del transtorno

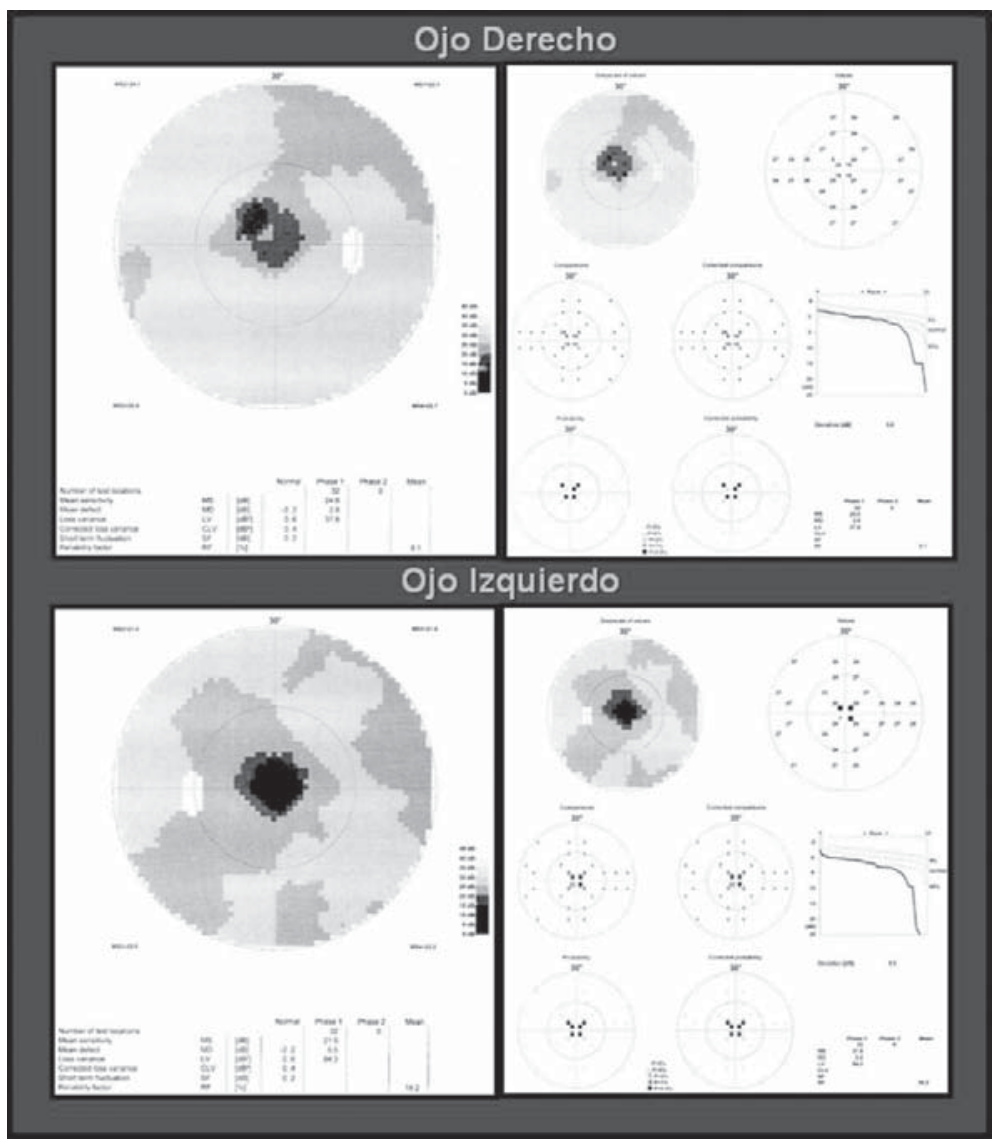

Figura 1. Campimetría bilateral: escotoma central. 


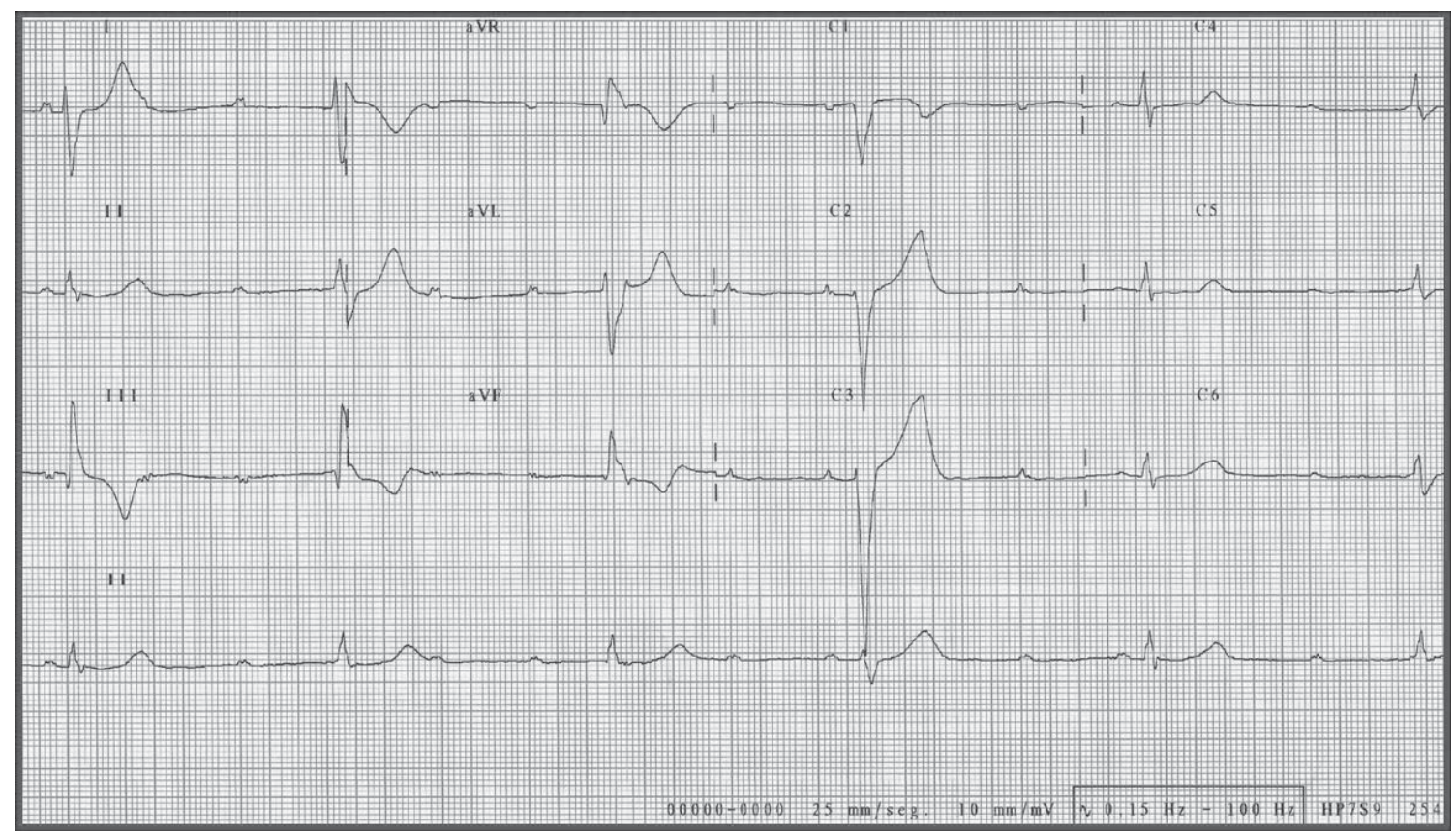

Figura 2. ECG: bloqueo auriculoventricular completo.

de conducción, la paciente requirió del implante de un marcapasos definitivo VDDR, sin complicaciones.

Se consideró que esta paciente presentó una toxicidad ocular y cardiaca por cloroquina, manifestada como retinopatía bilateral y bloqueo auriculoventricular completo sintomático.

Los antipalúdicos de síntesis, incluyendo la cloroquina, son frecuentemente utilizados en el tratamiento de diversas enfermedades sistémicas y cutáneas, como el lupus eritematoso sistémico. La mayor parte de sus reacciones adversas son dependientes de la dosis, especialmente de la dosis acumulada, que depende principalmente de la duración del tratamiento. Las manifestaciones de toxicidad farmacológica más frecuentes son trastornos digestivos leves, pero también pueden ocasionar digestopatías importantes, así como alteraciones sensoriales, cutáneas, neurológicas, musculares y oftalmológicas ${ }^{1}$, de las cuales la retinopatía es infrecuente dado que aparece en 0,01 al $0,1 \%$ de los casos; excepcionalmente se producen trastornos cardiológicos, estimándose que aparecen en $<0,01 \%$ de los casos, y ya de forma realmente extraordinaria un mismo paciente asocia afectación por antimaláricos de síntesis del tipo retinopatía y bloqueo auriculoventricular.

La toxicidad cardiaca por fármacos antipalúdicos de síntesis puede manifestarse como una miocardiopatía, con o sin insuficiencia cardiaca, así como con diversos grados de trastornos del sistema de conducción cardiaco, de entre los cuales el BAVC sintomático constituye una de las manifestaciones más graves, y suele aparecer tras un tratamiento prolongado (de 2 a 30 años) y con dosis de fármaco acumuladas elevadas (de $100 \mathrm{a}$ $5.000 \mathrm{~g})^{2}$. De forma distinta a lo que ocurre con la retinopatía, que en ocasiones resulta reversible tras cesar el tratamiento ${ }^{3}$, la evolución de las manifestaciones cardiacas es muy incierta de modo que la mayoría del escaso número de pacientes reportados que presentan un BAVC sintomático requirieron del implante de un marcapasos definitivo para su tratamiento ${ }^{4,5}$.

Dado que la toxicidad de estos fármacos depende principalmente de la dosis acumulada muchos casos podrían evitarse al no superar la dosis máxima segura, y en el caso de producirse dicha toxicidad, en ocasiones podría ser reversible si se diagnostica a tiempo y se suspende el uso del fármaco causal. Es por esto que diversas sociedades médicas han establecido recomendaciones 
acerca de los controles que hay que realizar a los pacientes tratados con antipalúdicos de síntesis. A pesar de ello, y de ser bien conocida la toxicidad por cloroquina, aún aparecen nuevos casos, lo que lleva a enfatizar la importancia que los pacientes con enfermedades reumatológicas sean estudiados antes y durante el tratamiento con fármacos antipalúdicos de síntesis mediante controles oftalmológicos y electrocardiográficos seriados, a fin de detectar precozmente los signos de toxicidad.

Dra. Delicia I. Gentille Lorente Servicio de Cardiología, Hospital de Tortosa "Verge de la Cinta". IISPV. Tortosa, Tarragona, España.

\section{Referencias}

1. Costedoat-Chalumeau N, Hulot JS, Amoura Z, Leroux G, Lechat P, Funck-Brentano C, Piette JC. Heart conduction disorders related to antimalarials toxicity: an analysis of electrocardiograms in 85 patients treated with hydroxychloroquine for connective tissue diseases. Rheumatology 2007; 46 (5): 808-10.
2. Sánchez J, Ocaña C, García FJ, González R, Garrido R, Colorado R, et al. Bloqueo auriculoventricular completo en pacientes adultos con lupus eritematoso sistémico. Casuística propia y revisión de la bibliografía. Reumatol Clin 2006; 2(6): 294-7.

3. Ferreras A, Pinilla I, Abeca E, Pajarín AB, Honrubia FM. Toxicidad retiniana secundaria a tratamiento con cloroquina. Arch Soc Esp Oftalmol 2007; 82: 103-8.

4. Reuss-Borst M, Berner B, Wulf G, Müller GA. Complete heart block as a rare complication of treatment with chloroquine. J Reumatol 1999; 26(6): 1394-5.

5. Alkmim R, Martinelli M, Benvenuti LA, Costa R, Pedrosa AA, Nishióka SA. Cardiac damage from chronic use of chloroquine. A Case report and review of the literature. Arq Bras Cardiol 2002; 79 (1): 85-8.

\section{Correspondencia a:}

Dra. Delicia I. Gentille-Lorente. Servicio de Cardiología.

Hospital de Tortosa "Verge de la Cinta". IISPV. C/ Esplanetes 14.

CP 43500. Tortosa Tarragona (España).

Teléfono: (0034) 977519105.

E-mail: dgentille.ebre.ics@gencat.cat 